\title{
Cell-cycle Checkpoints and Aneuploidy on the Path to Cancer
}

\author{
ELIZABETH S. WENZEL and AMARESHWAR T. K. SINGH \\ Department of Biology, Division of Natural and Social Sciences, Carthage College, Kenosha, WI, U.S.A.
}

\begin{abstract}
The cell cycle is a complex sequence of events through which a cell duplicates its contents and divides, and involves many regulatory proteins for proper cellular reproduction, including cyclin proteins and cyclin-dependent kinases, oncogenes and tumor-suppressor genes, and mitotic checkpoint proteins. Mutations of any of these regulatory mechanisms can lead to reproduction of cells carrying genetic mutations or abnormal numbers of chromosomes, resulting in genomic instability. Chromosomal instability, contributing to genomic instability, refers to abnormalities in the number of chromosomes, and leads to aneuploidy. The role of aneuploidy in cancer cell development is often disputed, as conflicting hypotheses and research make it unclear as to whether aneuploidy is a cause or consequence of cancer. Here, we present an overview of the importance of cell-cycle checkpoint regulation and chromosomal instability in the development of cancer, and discuss evidence for conflicting arguments for the role of aneuploidy in cancer, leading us to conclude that further investigation of this role would benefit our understanding of cancer development.
\end{abstract}

The cell cycle is a complex sequence of events through which a cell duplicates its contents and divides, resulting in two genetically identical daughter cells. This cycle, and its regulation, is essential to cell growth and reproduction, and involves many regulatory proteins such as cyclin proteins and cyclin-dependent kinases (CDKs), oncogenes and tumorsuppressor genes in interphase, and mitotic checkpoint proteins that allow stages of the cell cycle to proceed, or

This article is freely accessible online.

Correspondence to: Dr. Amareshwar T.K. Singh, Associate Professor of Biology, Carthage College, Kenosha, WI 53140, U.S.A. Tel: +1 2625516327, e-mail: asingh1@carthage.edu

Key Words: Cell-cycle checkpoints, cancer, regulation, cyclins, cyclin-dependent kinases, aneuploidy, review. inhibit this procession. Mutations and deficiencies in regulation throughout the cell cycle, however, can lead to serious diseases such as cancer. This review compares the cell cycle in normal cells to that in cancer cells, with a focus on the regulatory proteins involved, and the role of deficiencies in these proteins in the development of cancer.

\section{The Cell Cycle in Normal Cells}

The cell cycle comprises of interphase, which consists of the $\mathrm{G}_{1}, \mathrm{~S}$, and $\mathrm{G}_{2}$ phases, and the mitotic (M) phase (1). During interphase, a cell prepares for division by means of growth and DNA replication. The $G_{1}$ phase is the gap between the end of cytokinesis of a previous division and the beginning of $\mathrm{S}$ phase, and is the phase in which the cell grows in preparation for DNA replication, as well as the phase in which it is decided whether a cell will divide again or enter $\mathrm{G}_{0}$, a resting phase. A removal of growth factors in early $G_{1}$ will send the cell into $G_{0}$, but their removal later on in $G_{1}$, after the restriction checkpoint, will allow the cell to continue into $S$ phase (2). During S phase, DNA replication occurs and each chromosome is duplicated, becoming two sister chromatids. G2 marks the gap between the end of S phase and the start of mitosis. Here, the cell synthesizes materials needed for mitosis, such as RNA and proteins (3).

The $\mathbf{M}$ phase begins with mitosis, which is subdivided into five phases, namely prophase, prometaphase, metaphase, anaphase and telophase, and ends in cytokinesis (1). Reproduction through the cell cycle results in genetically identical daughter cells.

\section{Regulation of the Cell Cycle}

Throughout these phases of the cell cycle, regulation is essential in the proper production of daughter cells. The fundamental aspect of regulation lies in cyclin proteins and cyclin-dependent kinases (CDKs), which form complexes and catalyze progression through the cell cycle when activated (2). As a result of the systematic synthesis and destruction of cyclin throughout the cycle, CDKs are only 
activated at certain times within the cell cycle, a key factor in cell-cycle regulation (4). Once activated by cyclins, CDKs phosphorylate specific substrates that drive events of the cell cycle and cell division.

These regulatory roles of cyclin-CDK complexes allow for 'checkpoints' during the cell cycle. Cell-cycle checkpoints are responsible for ensuring that each earlier process has been completed before the cell moves on to the next phase of the cycle. Activation of a checkpoint, meaning a possible error has been detected, arrests the cell cycle in its current phase through changes in CDK levels and activation, preventing improper cellular reproduction. Regulatory checkpoints include the $G_{1} / S$ or restriction checkpoint, the $G_{2} / M$ or DNA replication checkpoint, and the metaphase/anaphase or spindle apparatus checkpoint. The restriction checkpoint is influenced primarily by growth factors, cell size, cell nutrition, and DNA damage $(2,5)$. The DNA replication checkpoint is primarily influenced by improper DNA replication and damage, and the metaphase/ anaphase checkpoint is influenced by chromosome attachment to the mitotic spindle (1). Should any processes be found incomplete, or damage be evident at these checkpoints, cyclin-CDK regulatory activity is blocked, preventing the cell from progressing through the cycle until these issues are resolved and the cell is prepared for the next phase $(1,6)$.

Specifically, three CDKs are involved in regulation during interphase (CDK2, CDK4, and CDK6), regulating exit from and entrance into sub-phases (7). Detection of DNA damage signals the inhibition of these CDKs, inducing cell-cycle arrest. CDK4 and CDK6 activation influences the progression of $G_{1}$ early on, binding with cyclin-D to phosphorylate $\mathrm{pRb}$, the retinoblastoma protein, preventing it from binding and inhibiting the E2F transcription factor, which transcribes the necessary proteins for the $G_{1} / S$ transition and promotes the cell to the next phases of the cycle. $\mathrm{pRb}$ is responsible for inactivating E2F during phases such as $\mathrm{G}_{0}$ and $\mathrm{M}$. When CDK4 and CDK6 are inhibited at the detection of DNA damage, therefore, they do not inactivate $\mathrm{pRb}$, allowing it to bind to and inhibit E2F and preventing the transcription of necessary proteins, a process that resumes when the checkpoint deems the cell to be properly prepared (7). CDK2 is also involved in the inactivation of $\mathrm{pRb}$, and also plays a role in DNA repair and replication, phosphorylating substrates necessary for DNA replication $(8,9)$.

\section{Cell-cycle Regulation and Cancer Oncogenes and Tumor Suppressors}

Oncogenes and tumor-suppressor genes play a large role in regulation of the cell cycle, particularly those of the p53 and $\mathrm{pRb}$ pathways, which are involved in the restriction checkpoint. p53, a tumor-suppressor protein, responds to DNA damage during $G_{1}$ such as mismatches and single-stranded DNA, initiating transcription of $p 21$, a CDK-interacting protein that inhibits activation of the necessary CDKs of G1 to phosphorylate $\mathrm{pRb}$, and therefore preventing progression to DNA synthesis (11). p53 is also highly involved in apoptosis in cases of irreparable damage (12). Mutations in p53 are extremely common in human cancer, and result in lack of $p 21$ transcription and therefore dysfunctional or lack of arrest of G1 in the presence of DNA damage, allowing this damage to continue on in the cycle without repair (13). Evidence of this p53 dependence during $G_{1}$ has been shown through studies of p53-null transgenic mice, and failure of their cells to arrest during $\mathrm{G}_{1}$ when faced with DNA damage (14). As a result, the mutation or damage becomes permanent in the genome (2). Studies of mutations in $p 53$, which are often accompanied by conformational changes of the protein that allow for detection of these mutations (11), in mice have shown mutant p53 to result in susceptibility to tumors such as lung adenocarcinomas, osteosarcomas, and lymphomas (15).

Related to the p53 tumor suppressor, the murine double minute-2 (MDM2) oncogene is also involved in the DNA damage checkpoint. MDM2 proteins abrogate the checkpoint by binding to mutated, wild-type p53 and inhibiting its function through these interactions $(16,17)$.

$\mathrm{pRb}$, discussed previously, is another tumor suppressor, and a target of CDKs (CDK2, CDK 4, and CDK6) involved in $\mathrm{G} 1$ and the restriction checkpoint $(5,18)$. Defective $\mathrm{pRb}$ function results in a lack of binding to E2F, which then is allowed to transcribe such proteins without regulation and promote the cell through the cycle (19).

Cyclin D1 has been shown to be amplified in cancer such as breast cancer (20). Cyclin D1 affects the function of $\mathrm{pRb}$ through bonding with CDK 4 and CDK6, which phosphorylate $\mathrm{pRb}$.

\section{Aneuploidy and Cancer}

Another source of development of cancer and tumorigenesis lies in defective regulation during mitosis. Aneuploidy involves the presence of an abnormal number of chromosomes in a cell, and is an extremely common characteristic of tumor cells involving chromosomal instability $(21,22)$. Chromosomal instability refers to an increased rate in chromosomal abnormalities, such as deletions or duplications, leading to an unequal distribution of DNA in daughter cells. High rates of chromosomal instability can lead to aneuploidy, which is often observed in cancer. For example, whole chromosome gains, such as the gain of chromosome 8 , have been found as a common error in karyotype in acute myeloid leukemia (23).

One hypothesis as to why this abnormal segregation of chromosomes may lead to tumor development is that should 
a cell be missing parts of or whole chromosomes, they also lose regulatory genes included in those parts, such as tumorsuppressor genes (24). These abnormal numbers may also result in aberrant gene expression and varying levels of genomic instability (25).

Studies suggest that a normal cell, such as one from the RPE-1 or HCT116 cell line, missegregates a chromosome once in every one hundred rounds of division (26). These missegregations are thought to be caused by errors surrounding the spindle checkpoint, such as abnormal centrosome numbers and incorrect kinetochore-microtubule attachments. For example, merotelic attachments, in which one single kinetochore of a sister chromatid pair is attached to microtubules from both poles of the cell, may arise from an excess number of centrosomes (27). Ganem et al. suggested through generation and imaging of cells that differed in centrosome numbers that extra chromosomes result in high frequencies of merotelic attachments and missegregation leading up to anaphase (27). It is especially important to look into the mechanisms surrounding the spindle checkpoint, as the cell cycle is reliant upon this checkpoint to ensure proper segregation of chromosomes prior to division.

Before anaphase and chromosomal segregation begins, sister chromatids are held together by cohesin, a protein complex (28). The proteolysis of sister chromatid cohesion 1 (SCC1), a cohesin subunit, by separase, a protease, triggers anaphase and chromosomal segregation. Once proper attachment of chromosomes to the spindle fibers is confirmed, a separase inhibitor called securin is ubiquitinated by the anaphase-promoting complex or cyclosome APC/C. Without securin to inhibit separase, it is activated, proteolysis of SCC1 occurs, and anaphase begins (28). Upon detection of improper connection of chromosomes to the spindle apparatus at kinetochores, it is thought that these kinetochores send out a checkpoint signal to arrest the cell cycle, signaling the inhibition of APC/C, and therefore inhibiting segregation (29, 30). Studies involving laser ablation of one unattached kinetochore showed that a cell could proceed on through mitosis when ablation occurred, suggesting that unattachment is the source of the inhibitory signal (29).

While complete failure at this spindle checkpoint leads to cell death (31), impairments in, but not failure of, the checkpoint resulting from defects surrounding the proteins involved in this process have been found in tumor cells. These proteins, after detection of incorrect attachment of chromosomes to the spindle apparatus, inhibit the procession of steps surrounding $\mathrm{APC} / \mathrm{C}$, therefore preventing the initiation and promotion of segregation and anaphase. The ubiquination abilities of $\mathrm{APC} / \mathrm{C}$ are dependent on the binding of the cell division cycle protein 20 (CDC20), which recruits substrates to $\mathrm{APC} / \mathrm{C}$ and activates the process (32). Other proteins involved in a functioning spindle checkpoint include the mitotic arrest deficient protein 2 (MAD2) and the budding uninhibited by benzimidazole-related protein 1 (BUBR1). MAD2 binds to CDC20, inhibiting the protein and preventing the ubiquination of securin by APC/C (33). BUBR1 also inhibits the APC/C and CDC20 complex, independently of MAD2 (33). Alterations in the expression of these checkpoint proteins can result in incorrect segregation of chromosomes due to failure to arrest before corrections can be made, leading to aneuploidy. These aberrant chromosome numbers are often seen in cancer, evidenced by the commonality of spindle checkpoint deficiency in tumor cells (22).

Mutations in checkpoint proteins have often been found in association with colorectal cancer, tumor cells of which have commonly been found to show evidence of aneuploidy due to chromosomal instability $(22,31,34)$. Additionally, $\mathrm{Li}$ and Benezra reported that a breast cancer cell line with reduced MAD2 level (T47D) failed to arrest at the spindle checkpoint in response to inhibitory effects on the spindle apparatus (35). Mutations or dysregulation of other checkpoint proteins such as budding uninhibited by benzimidazole protein 1 (BUB1) and BUBR1 have also been observed in colorectal and lung cancer, as well as in leukemia and lymphoma (36-38). Gemma et al. screened the DNA sequences of human lung cancer cell lines for mutations in the $B U B 1$ gene, and found various alterations to this gene in some of these cell lines (36). Ohshima et al. found mutations or deletions in the BUB1 and BUBR 1 genes in adult T-cell leukemia/lymphoma (37). Shichiri et al. found irregularities in the expression of BUB 1 and BUBR 1 in colorectal cancer, and concluded that the abnormal expression of these checkpoint genes may lead to aneuploidy and tumor metastasis (38).

\section{The Role of Aneuploidy in Cancer Development}

While more and more is being discovered regarding these protein irregularities resulting in improper spindle checkpoint function, the question still persists of whether aneuploidy is a cause or a consequence of cancer and tumor development. An argument for aneuploidy as a consequence, rather than a cause, of cancer lies in the knowledge that the commonly found mutations in regulatory pathways such as the p53 and pRb pathways lead to genomic and chromosomal instability, and that the frequent aneuploidy in cancer cells is a result of this chromosomal instability (39). Manning et al. showed that depletion of $\mathrm{pRb}$, which as discussed above can cause errors at the restriction checkpoint, also results in errors in the structure of centromeres, leading to higher frequencies of merotelic attachment and therefore higher rates of improper chromosomal segregation. This ultimately can lead to abnormalities involving whole-chromosome losses/gains 
(40). In these cases, aneuploidy results from alternative forms of instability, and, although it affects the development of these cells, it is a consequence of other causes.

On the other hand, studies involving the observation of chromosome numbers in cancer cell lines, such as trisomy of certain chromosomes, show a resultant duplication of mutated alleles, connecting aneuploidy to tumorigenesis (41, 42). Beghini et al. suggested that trisomy of chromosome 4 leads to the duplication of the mutant tyrosine kinase receptor (KIT) allele observed in acute myeloid leukemia (41), and Zhuang et al. observed duplication of another mutated tyrosine kinase receptor (MET) allele resulting from trisomy of chromosome 7 in papillary renal carcinoma (42).

In general, the particular role that aneuploidy plays in cancer development is still unclear, and as is whether it contributes to the causes of cancer or is a result of other causes. Future investigations of these phenomena should improve our understanding of cell-cycle regulation in cancer cells, and may point to newer approaches to treating cancer.

\section{Conclusions and Future Directions}

There are varying underlying mechanisms by which cell division and reproduction is regulated. Dysregulation of these mechanisms can have detrimental and even lethal effects on a cell and on the body. Uncorrected mistakes in the cell cycle, including DNA damage and mutations or improper chromosomal segregation and aneuploidy, result in genomic instability, a distinct characteristic of cancer. Knowledge of the means by which tumorigenesis occurs is important in exploring treatments of, and eventually cure of, cancer. Discussion of the role of aneuploidy in cancer development points to an area for which more research is encouraged, and also to an area which may offer an important piece in completing the puzzle to explain cancer development.

\section{Conflicts of Interest}

The Authors declare no competing financial interests.

\section{Acknowledgements}

The Authors gratefully acknowledge support from the Department of Biology, Division of Natural and Social Sciences, Carthage College, Kenosha, WI 53140 towards conducting the research.

\section{References}

1 Morris J, Hartl D, Knoll A, Lue R, Berry A, Biewener A, Farrell B, Holbrook N, Pierce N and Viel A: Biology: How Life Works. New York: Macmillan Higher Education, 2013.

2 Schafer KA: The cell cycle: a review. Vet Path 35: 461-478, 1998.
3 Baserga R: A study of nucleic acid synthesis in ascites tumor cells by two-emulsion autoradiography. J Cell Biol 12: 633-637, 1962.

4 Darzynkiewicz A, Gong J, Juan G, Ardelt B and Traganos F: Cytometry of cyclin proteins. Cytometry Pt A 25(1): 1-13, 1996.

5 Zetterberg A, Larsson O and Wiman KG: What is the restriction point? Curr Opin in Cell Biol 7(6): 835-842, 1995.

6 Pines J: Cyclins and cyclin-dependent kinases: theme and variations. Adv Cancer Res 66: 181-212, 1995.

7 Malumbres $\mathrm{M}$ and Barbacid M: Cell cycle, CDKs and cancer: a changing paradigm. Nat Rev Cancer 9: 153, 2009.

8 Satyanarayana A, Berthet C, Lopez-Molina J, Coppola V, Tessarollo L and Kaldis P: Genetic substitution of Cdk1 by Cdk2 leads to embryonic lethality and loss of meiotic function of Cdk2. Development 135: 3389-3400, 2008.

9 Sherr CJ and Roberts JM: CDK inhibitors: positive and negative regulators of G1-phase progression. Genes Dev 13: 1501-1512, 1999.

10 Kastan MB and Bartek J: Cell-cycle checkpoints and cancer. Nature 432: 316-323, 2004.

11 Nataraj AJ, II JCT and Ananthaswamy HN: p53 gene mutations and photocarcinogenesis. Photochem Photobiol 62(2): 218-230, 1995.

12 Clarke AR, Gledhill S, Hooper ML, Bird CC and Wyllie AH: p53 dependence of early apopototis and proliferative responses within the mouse intestinal epithelium following gammairradiation. Oncogene 9(6): 1767-1773, 1994.

13 Greenblatt MS, Bennett WP, Hollstein M and Harris CC: Mutations in the p53 tumor suppressor gene: clues to cancer etiology and molecular pathogenesis. Cancer Res 54: 4855-4878, 1994.

14 Yao SL, Akhtar AJ, Mckenna KA, Bedi GC, Sidransky D, Mabry M, Ravi R, Collector M, Jones R, Sharkis S, Fuchs E and Bedi A: Selective radiosensitization of p53-deficient cells by caffeine-mediated activation of $\mathrm{p} 34 \mathrm{cdc} 2$ kinase. Nat Med 2: 1140-1143, 1996.

15 Lavigueur AS, Maltby W, Mock D, Rossant J, Pawson T and Bernstein A: High incidence of lung, bone, and lymphoid tumors in transgenic mice overexpressing mutant alleles of the p53 oncogene. Mol Cell Biol 9: 3982-3991, 1989.

16 Finlay CA: The mdm-2 oncogene can overcome wild-type p53 suppression of transformed cell growth. Mol Cell Biol 13: 301306, 1993.

17 Haines DS, Landers JE, Engle LJ and George DL: Physical and functional interaction between wild-type p53 and $\mathrm{mdm} 2$ proteins. Mol Cell Biol 14: 1171-1178, 1994.

18 Malumbres M and Barbacid M: To cycle or not to cycle: a critical decision in cancer. Nat Rev Cancer 1: 222-231, 2001.

19 Arroyo M and Raychaudhuri P: Retinoblastoma-repression of E2F-dependent transcription depends on the ability of the retinoblastoma protein to interact with $\mathrm{E} 2 \mathrm{~F}$ and is abrogated by the adenovirus E1A oncoprotein. Nucleic Acids Res 20: 59475954, 1992.

20 Zhang SY, Caamano J, Cooper F, Guo W and Klein-Szanto AJ: Immunohistochemistry of cyclin D1 in human breast cancer. Am J Clin Pathol 102: 695-698, 1994.

21 Jallepalli PV and Lengauer C: Chromosome segregation and cancer: cutting through the mystery. Nat Rev Cancer 1: 109, 2001.

22 Weaver BA and Cleveland DW: Does aneuploidy cause cancer? Curr Opin Cell Biol 18: 658-667, 2006. 
23 Paulsson $\mathrm{K}$ and Johansson $\mathrm{B}$ : Trisomy 8 as the sole chromosomal aberration in acute myeloid leukemia and myelodysplastic syndromes. Pathol Biol 55: 37-48, 2007.

24 Thiagalingam S, Laken S, Willson JK, Markowitz SD, Kinzler KW, Vogelstein B and Lengauer C: Mechanisms underlying losses of heterozygosity in human colorectal cancers. Proc Natl Acad Sci USA 98: 2698-2702, 2001.

25 Duesberg P, Rausch C, Rasnick D and Hehlmann R: Genetic instability of cancer cells is proportional to their degree of aneuploidy. Proc Natl Acad Sci USA 95: 13692-13697, 1998.

26 Thompson SL and Compton DA: Examining the link between chromosomal instability and aneuploidy in human cells. J Cell Biol 180: 665-672, 2008.

27 Ganem NJ, Godinho SA and Pellman D: A mechanism linking extra centrosomes to chromosomal instability. Nature 460(7252): 278-282, 2009.

28 Nasmyth K, Peters JM and Uhlmann F: Splitting the chromosome: cutting the ties that bind sister chromatids. Science 288: 1379-1384, 2000.

29 Rieder CL, Cole RW, Khodjakov A and Sluder G: The checkpoint delaying anaphase in response to chromosome monoorientation is mediated by an inhibitory signal produced by unattached kinetochores. J Cell Biol 130: 941-948, 1995.

30 Shah JV and Cleveland DW: Waiting for anaphase: Mad2 and the spindle assembly checkpoint. Cell 103: 997-1000, 2000.

31 Cahill DP, Lengauer C, Yu J and Riggins GJ, Willson JK, Markowitz SD, Kinzler KW and Vogelstein B: Mutations of the mitotic checkpoint genes in human cancers. Nature 392: 300303, 1998

32 Fang G, Yu H and Kirschner MW: Direct binding of CDC20 protein family members activates the anaphase-promoting complex in mitosis and G1. Mol Cell 2: 163-171, 1998.

33 Bharadwaj R and Yu H: The spindle checkpoint, aneuploidy, and cancer. Oncogene 23: 2016-2027, 2004.

34 Lengauer C, Kinzler KW and Vogelstein B: Genetic instability in colorectal cancers. Nature 386: 623-627, 1997.
$35 \mathrm{Li} \mathrm{Y}$ and Benezra R: Identification of a human mitotic checkpoint gene: hsMAD2. Science 247: 246-248, 1996.

36 Gemma A, Seike Y, Uematsu K, Hibino S, Kurimoto F, Yoshimura A, Shibuya M, Harris C and Kudoh S: Somatic mutation of the $h B U B 1$ mitotic checkpoint gene in primary lung cancer. Genes Chromosomes Cancer 29: 213-218, 2000.

37 Ohshima K, Haraoka S, Yoshioka S, Hamasaki M, Fujiki T, Suzumiya J, Kawasaki C, Kanda M and Kikuchi M: Mutation analysis of mitotic checkpoint genes ( $h B U B 1$ and $h B U B R 1)$ and microsatellite instability in adult T-cell leukemia/lymphoma. Cancer Lett 158: 141-150, 2000.

38 Shichiri M, Yoshinago K, Hisatomi H, Sugihara K and Hirata Y: Genetic and epigenetic inactivation of mitotic checkpoint genes $h B U B 1$ and $h B U B R 1$ and their relationship to survival. Cancer Res 62: 13-17, 2002.

39 Gordon DJ, Resio B and Pellman D: Causes and consequences of aneuploidy in cancer. Nat Rev Genet 13: 189, 2012.

40 Manning AL, Longworth MS and Dyson NJ: Loss of $p R B$ causes centromere dysfunction and chromosomal instability. Genes Dev 24: 1364-1376, 2010.

41 Beghini A, Ripamonti CB, Castorina P, Pezzetti L, Doneda L, Cairoli R, Morra E and Larizza L: Trisomy 4 leading to duplication of a mutated KIT allele in acute myeloid leukemia with mast cell involvement. Cancer Genet Cytogenet 119: 2631, 2000.

42 Zhuang Z, Park WS, Pack S, Schmidt L, Vortmeyer AO, Pak E, Pham T, Weil R, Sonja C, Lubensky I, Linehan W, Zbar B and Weirich G: Trisomy 7-harbouring non-random duplication of the mutant $M E T$ allele in hereditary papillary renal carcinomas. Nat Genet 20: 66-69, 1998.

Received September 21, 2017

Revised October 19, 2017

Accepted October 25, 2017 